\title{
Review of recent progress in studies on noise emanating from rail transit bridges
}

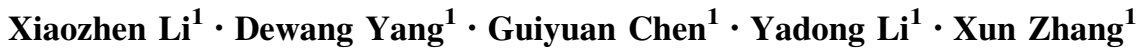

Received: 25 January 2016/Revised: 17 June 2016/ Accepted: 20 June 2016/Published online: 12 July 2016

(C) The Author(s) 2016. This article is published with open access at Springerlink.com

\begin{abstract}
In recent years, there has been rapid growth of Chinese rail transit networks. Many of these networks require elevated bridges. This results in a bridge-borne noise source, which occurs in addition to the main noise source (i.e., wheel-rail interactions). Bridge-borne noise is attracting increasing attention because of its low-frequency noise characteristics. This review paper first analyzes the space distribution, spectral characteristics, and sound pressure levels of noise radiated by all-concrete, steelconcrete composite, and all-steel bridges, mainly according to experimental studies. Second, this paper reviews existing theoretical prediction models of noise emanating from bridges: the semianalytical method, the Rayleigh integral method, the boundary element method, and statistical energy analysis. Several case studies are reviewed, and their results are discussed. Finally, according to the results of the current review, the main factors affecting bridgeborne noise are analyzed, several noise reduction measures are proposed for different types of bridges, and their effectiveness is demonstrated.
\end{abstract}

Keywords Rail transit · Bridge · Vibration · Noise · Noise control

Xun Zhang

zhxunxun@swjtu.edu.cn

Xiaozhen Li

xzhli@swjtu.edu.cn

Yadong Li

ydli@swjtu.edu.cn

1 Department of Bridge Engineering, School of Civil

Engineering, Southwest Jiaotong University,

Chengdu 610031, China

\section{Introduction}

When a train passes over a bridge, vibrations are generated owing to irregularities in the wheels and the track. These vibrations cause the wheels and track to radiate noise and transfer energy directly to each component of the bridge, causing the beams, piers, and other components to vibrate, thus forming secondary noise radiation. The magnitude of such bridge-borne noise can typically be $10 \mathrm{~dB}$ or more for common railway networks [1,2].

Bridges vary significantly in design and construction: those constructed from steel radiate mid- to high-frequency noise $(200-1,000 \mathrm{~Hz})$, while concrete bridgeborne noise is generally low-frequency noise $(<200 \mathrm{~Hz})$. Compared with high-frequency noise (such as wheel-rail noise), low-frequency noise has slower energy attenuation upon environmental radiation and is thus transmitted over longer distances. Low-frequency railway noise can easily pass through walls, windows, and other obstacles and can harm people's physical and mental health. Individuals subjected to environments characterized by chronic lowfrequency noise can suffer from insomnia, headache, tinnitus, discomfort, chest tightness, abdominal pressure, and other psychological and physical symptoms [3, 4]. A spectrum analyzer is necessary for quantitative monitoring of low-frequency noise, but there are currently no national testing standards or engineering norms regarding lowfrequency railway noise in China or several other countries. Therefore, manufacturers of low-frequency noise sources are still not legally regulated, while manufacturers of high-frequency noise sources are bound by legal responsibility.

Bridges have long service lifetimes and are difficult to replace or reconstruct. Thus, the problem of bridge-borne noise should receive due attention in the construction phase 
of rail transit bridges. The adoption of low-noise configurations and structures and appropriate noise reduction measures can help meet the requirements of national environmental standards. Therefore, investigations of noise from bridges and methodologies to mitigate such noise have recently attracted increasing research attention because of the rapid development of rail transit worldwide.

This paper reviews progress on experimental studies of bridge-borne noise by the authors and other investigators, including experimental studies of all-concrete, steel-concrete composite, and all-steel bridges. Then, theoretical/analytical prediction methods for noise from bridge vibrations are summarized, including the semi-analytical method, the Rayleigh integral method, the boundary element method (BEM), and statistical energy analysis (SEA). Finally, several noise reduction control measures are proposed and their effectiveness demonstrated.

\section{Experimental studies}

\subsection{Early research}

Bridge type, construction material, dimensions, and track structure influence bridge vibrations and bridge-borne noise. Early studies on radiant noise from bridge vibrations mainly employed field tests. With continual improvement of experimental techniques, the space distribution, spectral characteristics, and sound pressure level (SPL) of noise from bridge vibrations have been measured and potential noise reduction measures sought.

Stüber [5] tested the noise levels of two steel bridges with electric locomotives running at speeds of $80 \mathrm{~km} / \mathrm{h}$. The bridges were of the same structural type, but the tracks were ballasted on one and ballastless on the other; the noise level of the former was $13 \mathrm{~dB}(\mathrm{~A})$ lower than that of the latter. Then, with a layer of sand on the deck, an identical ballastless steel bridge showed a $7 \mathrm{~dB}(\mathrm{~A})$ decrease in noise level, indicating that improvements may result from the addition of dead weight and damping of the bridge deck. In 1966-1971, in order to classify the noise levels generated by different types of bridges, the Office for Research and Experiment (ORE) conducted tests similar to those of Stüber [6-9] to obtain the noise levels of different bridges. In Japan, Ban and Miyamoto [10] conducted a study on the noise reduction effects of ballast layers on concrete bridges; the results showed that the noise radiated underneath the bridge could be reduced by $7 \mathrm{~dB}(\mathrm{~A})$. Subsequently, Kurzweil [11] and Ungar and Wittig [12] gathered these test results according to such variables as nation, construction material, bridge structural type, and train type. That research made it possible to evaluate how noisy a particular bridge may be.
Walker et al. [13] conducted a noise comparison study of two cases, the first of which was a concrete bridge carrying light rail vehicles. The measured noise level was used as the target for a steel-concrete composite bridge to be built later. Finite element analysis used to predict the noise level of the steel-concrete composite bridge determined that low-frequency noise was the dominant component of the bridge-borne noise. To achieve a noise level similar to that of the concrete bridge, an elastic fastening system was used on the steel-concrete composite bridge. In the second case, they conducted noise and vibration tests on a bridge with elastic fastenings installed; noise was measured before and after the installation of noise barriers. The results showed that both the elastic fastening system and the noise barriers could effectively reduce noise levels; however, the noise reduction effect of the elastic fastening system was slightly less effective, because the main noise source was wheel-rail interactions.

According to Wang et al. [14], dynamic tests on a rigid frame bridge from the Sydney RSA line indicated that a train speed of $65 \mathrm{~km} / \mathrm{h}$ across a bridge with rigid baseplates under sleepers resulted in a noise level of $90 \mathrm{~dB}(\mathrm{~A})$ at $5.5 \mathrm{~m}$ from the track centerline at frequencies of 200-1,000 Hz. For a bridge with elastic baseplates under sleepers, the overall noise level, the vibration of the main girder in the vertical direction, and the lateral vibration were reduced by 6,10 , and $5 \mathrm{~dB}(\mathrm{~A})$, respectively.

The West Rail Line in Hong Kong was the first practical engineering project in which concrete box girder bridges generated a noise problem, because Hong Kong has strict noise control regulations. Tests by $\mathrm{Ngai}$ and $\mathrm{Ng}[15,16]$ on a concrete box girder bridge in Hong Kong indicated that a train speed of $140 \mathrm{~km} / \mathrm{h}$ resulted in noise and vibrations at frequencies of $20-157 \mathrm{~Hz}$ with resonance frequencies at 43 and $54 \mathrm{~Hz}$. Those peaks of structure-borne noise were mainly caused by the resonance of the concrete box girder. The analysis indicated that structural vibration resonance was more important than acoustic resonance in the generation of bridge-borne noise.

\subsection{Recent research}

\subsubsection{All-concrete bridges}

Box girder bridges are the most frequently used type of concrete bridge in China, and their construction has been associated with the rapid growth of high-speed rail and rail transit lines. Li et al. [17] and Zhang et al. [18] studied the vibration and noise levels of such bridges using in situ experiments conducted simultaneously on 32-m-long double-track and single-track box girders. The test high-speed train was a CRH1 with a configuration of five motor cars $(\mathrm{M})$ and three trailers $(\mathrm{T})$, i.e., $2(2 \mathrm{M}+1 \mathrm{~T})+(1 \mathrm{M}+1 \mathrm{~T})$. 
The unsprung masses of the locomotive and trailer wheelsets were 1,650 and $1,450 \mathrm{~kg}$, respectively.

Velocity and acceleration are ideal indices for evaluation of structural high-frequency vibration response. Vibrational energy is proportional to the square of vibration velocity and can cause damage/harm. In addition, vibratory velocity provides a useful description of the sound radiation from the vibrating structure. Therefore, vibratory velocity is used as a physical index of sound radiation in this paper, with a reference velocity of $10^{-9} \mathrm{~m} / \mathrm{s}$ for calculation of vibratory velocity level.

To demonstrate the spectral characteristics of bridge vibration and associated noise, Figs. 1 and 2 illustrate the vibratory velocity levels and SPLs of the bottom slabs when identical trains traveled on two different box girders at $144-160 \mathrm{~km} / \mathrm{h}$. More experimental results can be found in the studies of Li et al. and Zhang et al. [17, 18].

As illustrated in Fig. 1a, the maximum velocity level of a double-track box girder appears at $50 \mathrm{~Hz}$ and is accompanied by a few additional peak frequency bands at $1 / 3$ octave center frequency bins centered around frequencies such as 315 and $630 \mathrm{~Hz}$, where the velocity level is about $20 \mathrm{~dB}$ lower than that centered at $50 \mathrm{~Hz}$. The overall vibration of the bottom slab of the double-track box girder is concentrated below $100 \mathrm{~Hz}$, with 40,50 , and $63 \mathrm{~Hz}$ as the centers of the three strongest vibratory-velocity frequency bands.

Figure $1 \mathrm{~b}$ shows 18 vibration-velocity-level curves for the bottom slab of a single-track box girder. The center of the frequency band that produced the maximum bottomplate velocity level was $63 \mathrm{~Hz}$, accompanied by two weaker peak bands centered at 315 and $630 \mathrm{~Hz}$. The bottom slab's vibratory velocity level is concentrated at $100 \mathrm{~Hz}$, with the three strongest frequency bands of vibratory velocity level centered at 40,50 , and $63 \mathrm{~Hz}$, the same as those of the double-track box girder.

Figure 1a, b illustrate that the vibratory velocity level of the double-track box girder is about $5 \mathrm{~dB}$ higher than that of the single-track box girder. Zhang et al. [18] indicated that the reason for this was that the double-track box girder was wider than the single-track girder, while the slab thicknesses of the two box girders were nearly the same. This led to larger bending deformation along the cross section, resulting in higher local vibrations in the doubletrack box girder.

The SPL peaks in Fig. 2a, b show similar spectral characteristics, confirming that SPL is directly related to the box girder slabs' vibratory velocity. Bridge-borne noise is significant in the low-frequency range, reaching maxima centered at 50 and $63 \mathrm{~Hz}$ for the double-track and singletrack box girders, respectively. The difference in SPL between the two box girders was about $9 \mathrm{~dB}$, reflecting the important relationship between vibration and noise control.

The results by $\mathrm{Li}$ et al. [17] and Zhang et al. [18] indicated that the local stiffness of the box girder slabs, rather than the global stiffness of the box girder as a beam, determined bridge vibrations and associated noise at audible frequencies. Hereafter, more tests will be introduced and compared.

Chang [19] conducted a vibration test on a 25-m-long, simply supported concrete box girder (top width: $8.5 \mathrm{~m}$, bottom width: $4.18 \mathrm{~m}$, girder height: $1.53 \mathrm{~m}$ ) on Wuhan Urban Rail Transit Line 1. The measurement points were located at the bottom slab, web, and flange slab. The running train was a Metro $\mathrm{C}$ (dynamic axle weight: $13 \mathrm{t}$, trailer axle weight: $14 \mathrm{t}$ ) with four-car marshaling and running speed $50 \mathrm{~km} / \mathrm{h}$. The strongest vibrations appeared at the bottom and flange slabs, with the dominant frequencies of

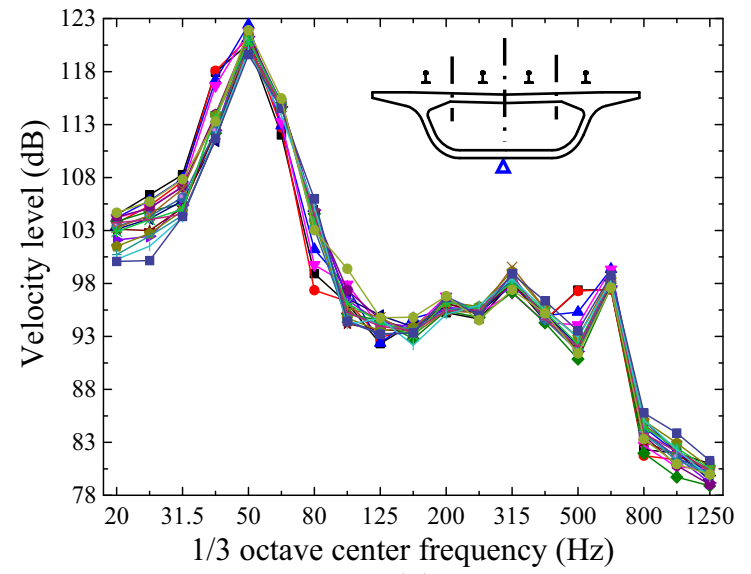

(a)

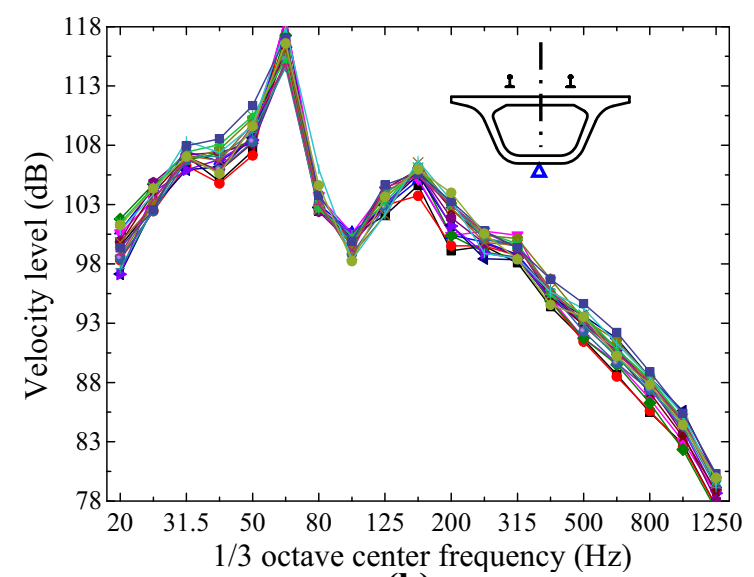

(b)

Fig. 1 Comparison of vibratory velocity levels for two box girders crossed by identical trains (see Zhang et al. [18]). a Double-track box girder, b single-track box girder 


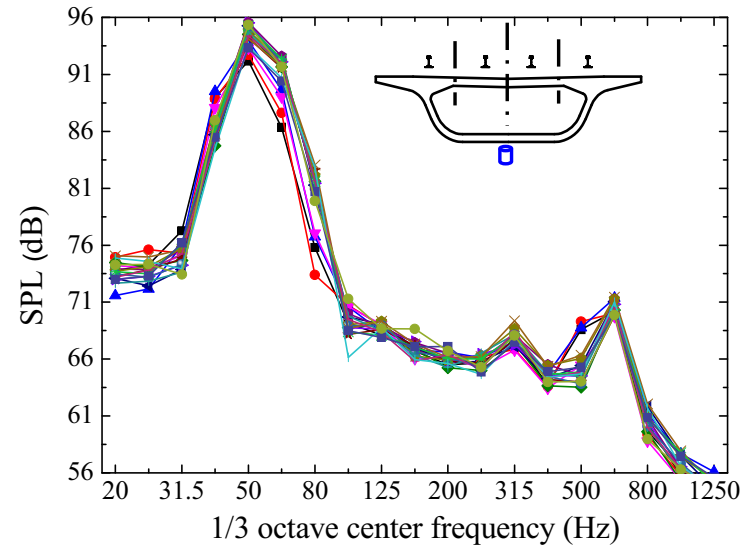

(a)

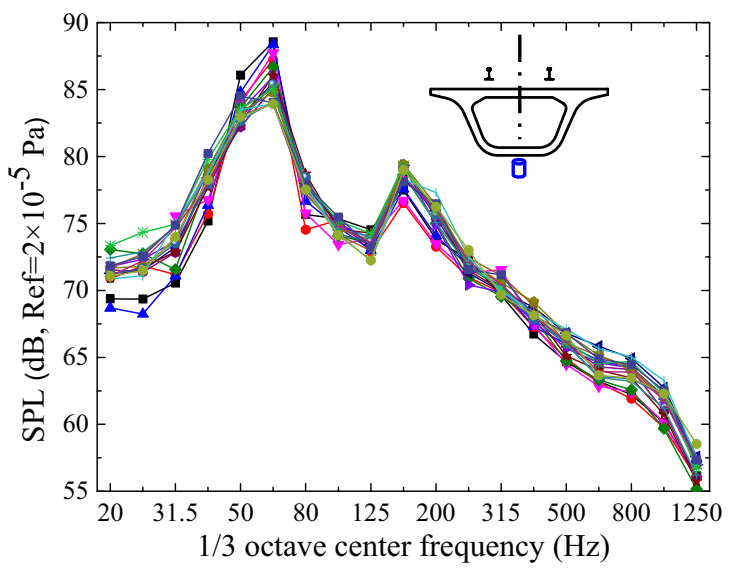

(b)

Fig. 2 Comparison of SPLs for two box girders crossed by identical trains (see Zhang et al. [18]). a Double-track box girder, b single-track box girder

vibrational energy at $40-90 \mathrm{~Hz}$. Gao et al. [20] tested a 25-m-long, simply supported concrete box girder (top width: $9.0 \mathrm{~m}$, bottom width: $4.3 \mathrm{~m}$ ) from the Beijing Airport Fast Rail Line. The running train was a linear induction motor train with four-car marshaling and running speed $70-90 \mathrm{~km} / \mathrm{h}$. The vibratory velocity level of the bottom slab had a dominant frequency range of $63-100 \mathrm{~Hz}$, and the vibration velocities of the box girder's web and bottom slab were about $20 \mathrm{~dB}$ smaller than that of the top slab.

U-shaped girders are becoming increasingly popular on urban rail transit lines because of the lower building height required, their shielding effect on wheel-rail noise, and their artistic shape. Li et al. [21] conducted in situ tests on a 30-m-long, concrete U-shaped girder (single-track, slab width: $3.63 \mathrm{~m}$, thickness: $0.24 \mathrm{~m}$, girder height: $1.8 \mathrm{~m}$ ) from Shanghai Rail Transit Line 8. The running train was a Metro $\mathrm{C}$ with six-car marshaling and locomotive and trailer wheelset weights of 1,900 and $1,150 \mathrm{~kg}$, respectively. The results of Li et al. [21] have been reprocessed here (Fig. 3).

Generally, the vibratory velocity levels of the web and the bottom slab of the U-shaped girder are concentrated in the frequency range 32-64 Hz. As train speed increases, vibratory velocity level increases gradually, and the frequency of the maximum vibratory velocity also increases (e.g., from the frequency band centered at $40 \mathrm{~Hz}$ to that at $50 \mathrm{~Hz}$ ). On the other hand, because of the open nature of U-shaped girders, the supporting effect of the two web slabs to the bottom slab is limited. Thus, the vertical vibratory velocity of the bottom slab is greater than that of the box girders, as shown in Fig. 1a, b, and the lateral vibratory velocity of the web slab is also high. Thus, even at lower operational speeds, U-shaped girders are likely to radiate more noise than box girders. For example, the simulation results of $\mathrm{Wu}$ and Liu [22] demonstrated that

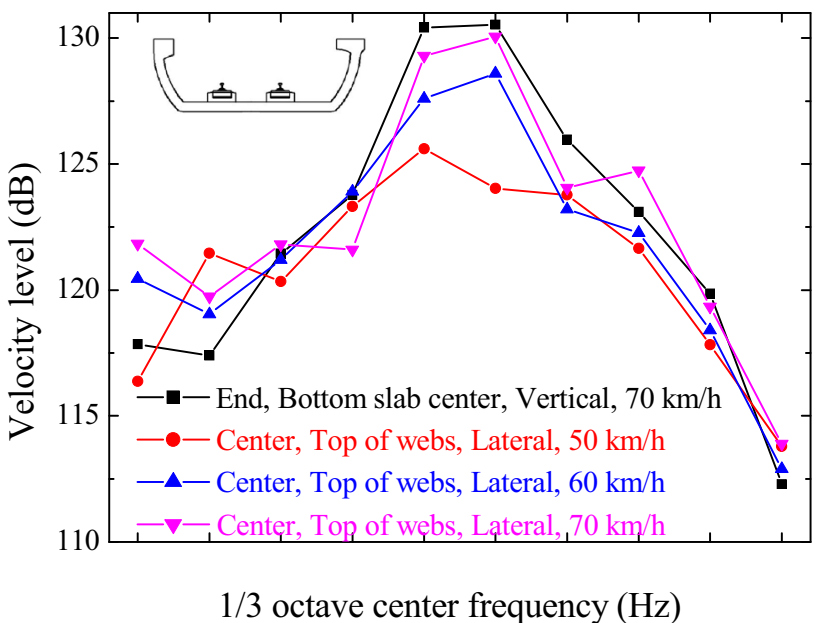

Fig. 3 Results reprocessed from Li et al. [21]

the structure-borne sound power radiated from a box-section viaduct was slightly lower (by $2.5 \mathrm{~dB}$ ) than that from a U-section viaduct. They concluded, considering the differences in train excitation and the acoustic measurement environment, that the A-weighted SPL measured from the $\mathrm{U}$-shaped structure should be about $2 \mathrm{~dB}$ higher than that from the box-section structure under the same excitation and acoustic conditions.

Thus, for both the box and U-shaped girders, the medium- and high-frequency vibrations of each slab are concentrated below $200 \mathrm{~Hz}$, with the frequency bin of maximum vibratory velocity level mainly centered at $31.5-80 \mathrm{~Hz}$ irrespective of train excitation. Moreover, although the energy from higher-frequency vibrations is transmitted from the track to the bridge structure with rapid attenuation, there are still some weaker vibration peaks. $\mathrm{Li}$ and $\mathrm{Wu}$ [23] reported that wheel-rail contact forces and power flows to the rail-bridge subsystem were primarily 
driven by contents around the natural frequency of a single wheel adhering to the elastically supported rail, providing a mechanism to determine the dominant frequencies of bridge vibrations. However, the local, natural vibrational characteristics of bridge slabs were ignored.

Chinese rail transit mostly uses box girder bridges, which have acoustic modes in the main frequency ranges of their interior cavities. These cavities' resonance may increase the noise radiated from the deck and bottom slab. Moreover, box girders' decks and bottom slabs have large areas with relatively high acoustic radiation efficiency. Zhang et al. [24] conducted theoretical and experimental studies on the acoustic modes of a 32-m-long, concrete box girder used on a high-speed railway line. The cavity resonance noise is shown in Fig. 4; at certain running speeds, there was a "beat" phenomenon inside the box, which can significantly increase the noise level inside, with a maximum instantaneous sound pressure up to $40 \mathrm{~Pa}$ and a peak frequency as $75 \mathrm{~Hz}$. The beat phenomenon of the noise in the box originated from the deck slab's vibration when its peak vibration frequency matched the box cavity's modal frequency. The cavity resonance noise of the box was greatly attenuated at the beam joint owing to acoustic leakage.

\subsubsection{Steel-concrete composite bridges}

Bewes [25] conducted noise tests on a steel-concrete composite bridge (a Light Rail Viaduct in Docklands), which had a multi-span continuous beam with a span length of about $16 \mathrm{~m}$ and a steel-concrete composite cross section, in 2005. The train was a B90/92 with six-car marshaling and velocity $54 \mathrm{~km} / \mathrm{h}$.

Figure 5 shows vibratory-acceleration measurement points $a_{1}$ and $a_{2}$, which were located on the concrete bridge decks on the track centerline, and points $a_{3}$ and $a_{4}$, which

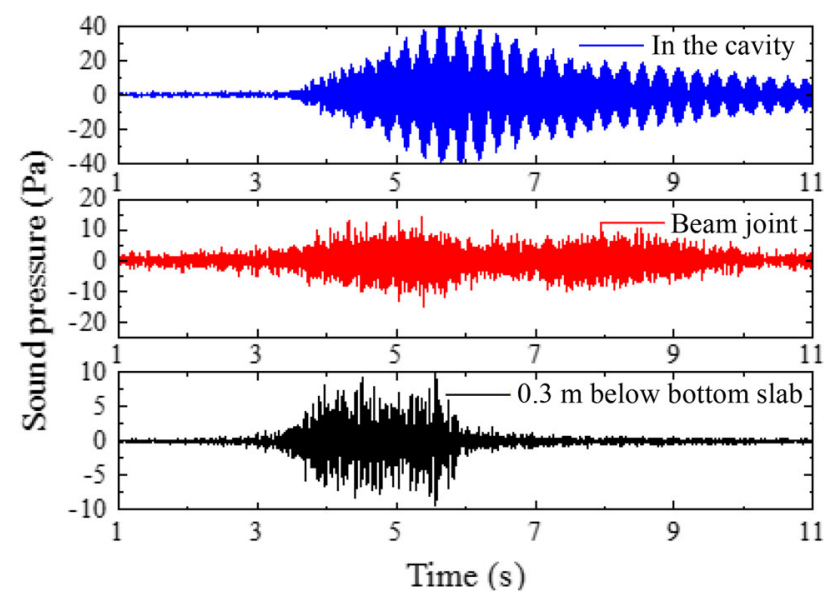

Fig. 4 Cavity resonance noise (see Zhang et al. [24])

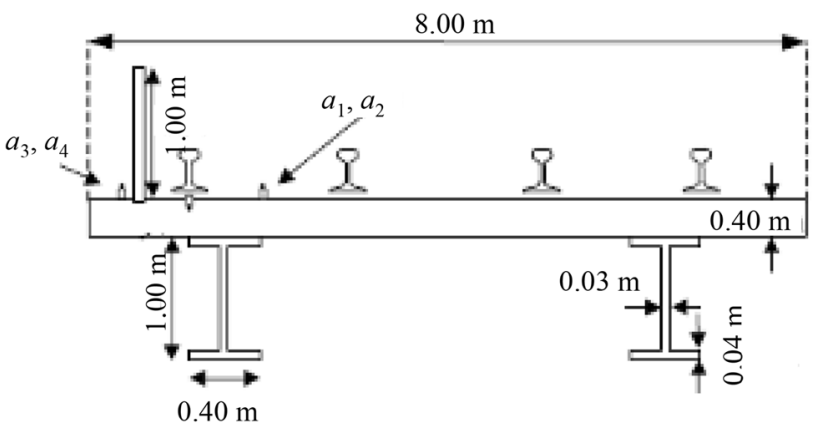

Fig. 5 Steel-concrete composite bridge in Docklands (see Bewes [25])

were located on sidewalk concrete bridge decks. The two noise measurement points, $M_{1}$ and $M_{2}$, are not shown in Fig. 5. $M_{1}$ was $7.5 \mathrm{~m}$ away from the near-track centerline and $1.2 \mathrm{~m}$ above the rail surface; $M_{2}$ was located below the bridge centerline, $1.2 \mathrm{~m}$ above the ground, and $6.8 \mathrm{~m}$ from the concrete bridge deck.

Figure 6 shows the vibratory velocity level at the bridge decks and the SPLs at the two measurement points, reprocessed from Bewes [25]. The bridge decks' vibratory velocity is mainly concentrated in the low-frequency band, the level of which attenuates rapidly with increasing frequency. The vibration frequency at the sidewalk bridge decks was larger than that at the track centerline in the range $25-125 \mathrm{~Hz}$ (peak frequency: $40 \mathrm{~Hz}$ ). The vibration of bridge decks at the track centerline is larger than that of the sidewalk at frequencies $>125 \mathrm{~Hz}$.

The measured noise at $M_{1}$ resulted from several kinds of noise sources, such as wheel-rail interactions. $M_{2}$ was located underneath the bridge; thus, the shielding effect of the bridge deck made it difficult for wheel-rail noise to spread to $M_{2}$. The results indicated that the frequency of bridge-borne noise can be as high as $500 \mathrm{~Hz}$ and that higher-frequency noise mainly comes from wheel-rail interactions.

In 2014, Liu [26] conducted noise tests on a steelconcrete composite continuous beam bridge on the Qinhuangdao to Shenyang Passenger Line (Fig. 7). The bridge's span was $(32+40+32) \mathrm{m}$, and the design load was ZK live load, equivalent to 0.8 times UIC load. The train passing the bridge was a CRH5 with measured speed $192 \mathrm{~km} / \mathrm{h}$. The measurement points are shown in Fig. 7.

The measured acceleration and SPL are shown at intervals of 1/3 octave in Fig. 8. The dominant acceleration frequency on the web and the bottom flange plate ranged from 50 to $1,000 \mathrm{~Hz}$. The peak frequencies of the acceleration on the web and bottom flange plate are 63 and $80 \mathrm{~Hz}$, respectively; the latter is higher because of the elevated stiffness of the bottom flange plate due to its greater thickness. 


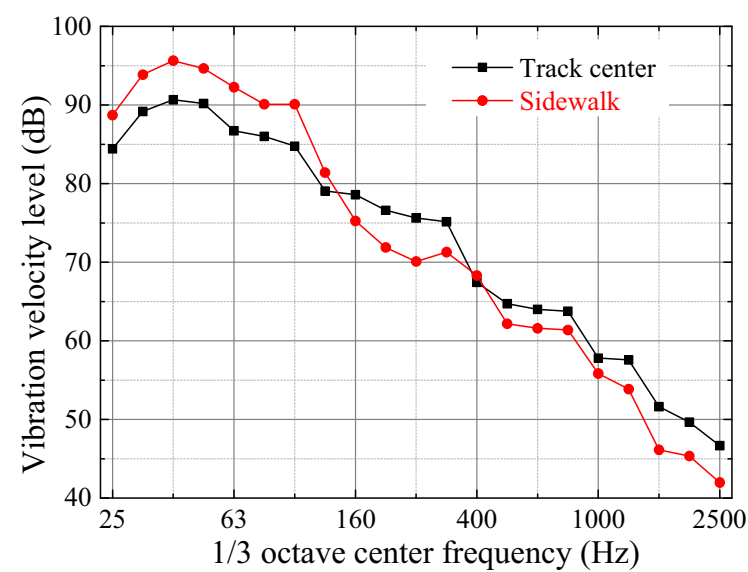

(a)

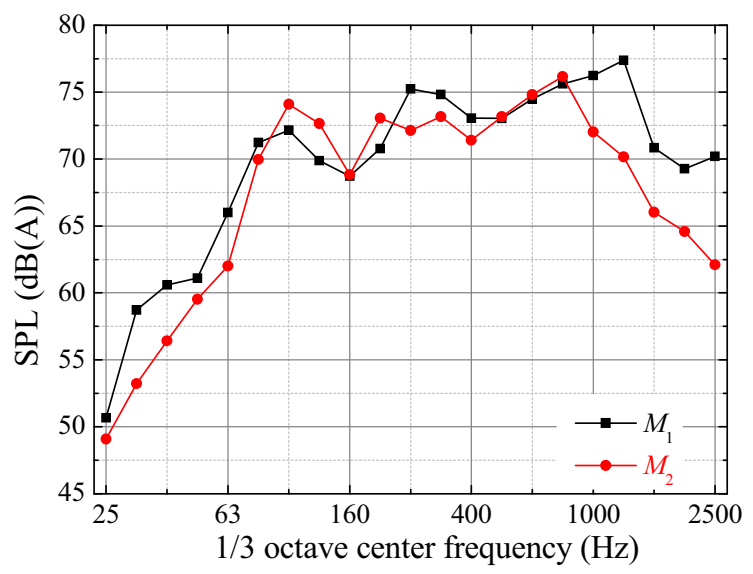

(b)

Fig. 6 Vibration and noise measurements reprocessed from Bewes [25]. a Vibration, b noise

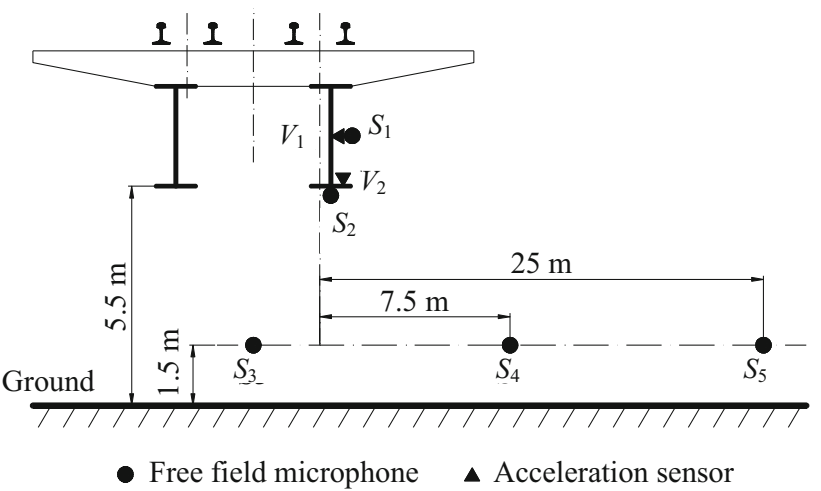

Fig. 7 Steel-concrete composite bridge on the Qinhuangdao to Shenyang Passenger Line (see Liu [26])

The peak frequency of the SPL ranges $40-125 \mathrm{~Hz}$, in agreement with the frequency range of the force transmitted from the track to the bridge [23]. The SPL at measurement point $S_{5}$ reaches its lowest level at $80-630 \mathrm{~Hz}$, where bridge-borne noise is dominant; the latter is attenuated with increasing distance. On the other hand, the SPL at $S_{5}$ is elevated above $800 \mathrm{~Hz}$, as this noise regime is mainly affected by wheel-rail interactions. The dominant frequency of the steel-concrete composite bridge noise ranges from 20 to $1,000 \mathrm{~Hz}$, while that of concrete box girders is often less than $100 \mathrm{~Hz}[17,18,27]$.

\subsubsection{All-steel bridges}

Bewes [25] conducted noise tests of a double-track steel bridge in 2005. The field points of the old Arsta Bridge were arranged in parallel with those of the new Arsta Bridge, but approximately $40 \mathrm{~m}$ apart. The total length of the old Arsta Bridge was about $650 \mathrm{~m}$, and it consisted of two parts: a deck-type concrete arch bridge and a halfthrough riveted steel bridge (span: $150 \mathrm{~m}$ ). The former had a ballast track, while the latter had open decks with wooden sleepers.

Three measurement points were arranged. $M_{1}$ (in the water under the bridge) and $M_{2}$ (on an island under the bridge) were aimed at the concrete bridge, whereas $M_{3}$ (in the water under the bridge) was aimed at the steel bridge; all three measurement points were located $1.5 \mathrm{~m}$ above the rail surface. The passing train was an X2000 with eight-car marshaling and a speed of $70 \mathrm{~km} / \mathrm{h}$.

Figure 9 shows the noise test results for the old Arsta Bridge. Although $M_{1}$ and $M_{2}$ were located above the water surface and ground, respectively, the SPL at frequencies above $125 \mathrm{~Hz}$ was very similar between the two locations. Thus, sound reflection from the ground or water under the bridge can be ignored. The noise level of the steel bridge is about $5 \mathrm{~dB}(\mathrm{~A})$ higher than that of the concrete bridge at $50-800 \mathrm{~Hz}$, indicating that noise from steel bridges is significantly louder than that from concrete bridges. The noise levels from concrete and steel bridges are similar above $1,000 \mathrm{~Hz}$, mainly because of the predominance of wheel-rail interaction noise in that range.

Bewes assumed that concrete bridge-borne noise can be ignored and that wheel-rail interaction noise is unchanged between different measurement points. The estimated steel bridge-borne noise can be obtained by subtracting that measured at $M_{3}$ from that measured at $M_{1} / M_{2}$ (Fig. 9). Steel bridge-borne noise is the main noise source at $50-800 \mathrm{~Hz}$, whereas that from wheel-rail interactions becomes the main noise source above $800 \mathrm{~Hz}$.

Poisson and Marguicchi [28] carried out noise tests on a single-track, simply supported steel truss bridge with span $20.8 \mathrm{~m}$, open decks, and wooden sleepers supported by two longitudinal beams. Field tests were performed on a variety 


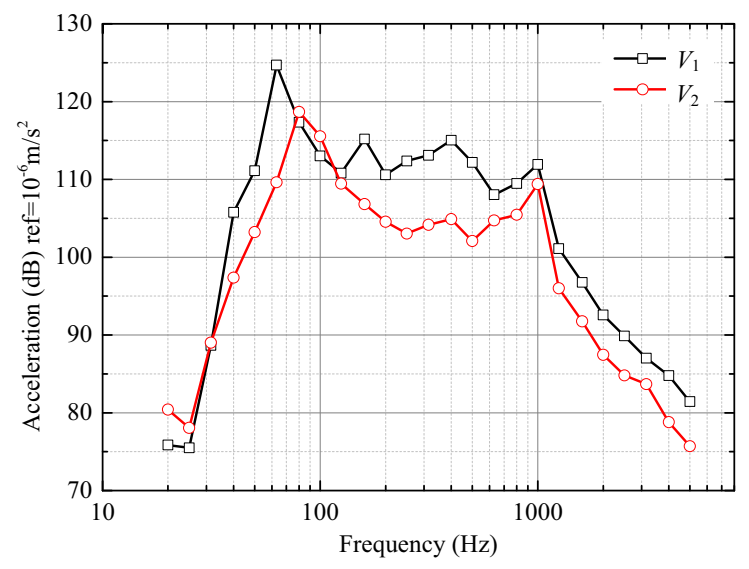

(a)

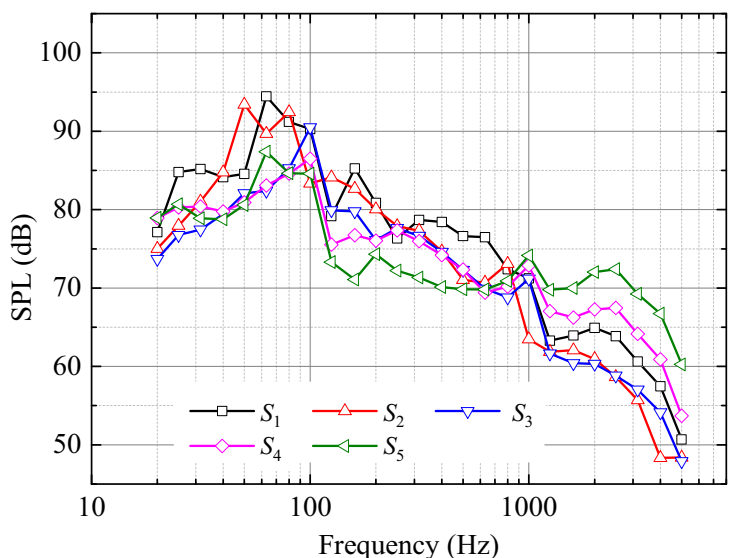

(b)

Fig. 8 Measured acceleration and SPL at train speed $192 \mathrm{~km} / \mathrm{h}$ (see Liu [26]). a Vibration, b noise

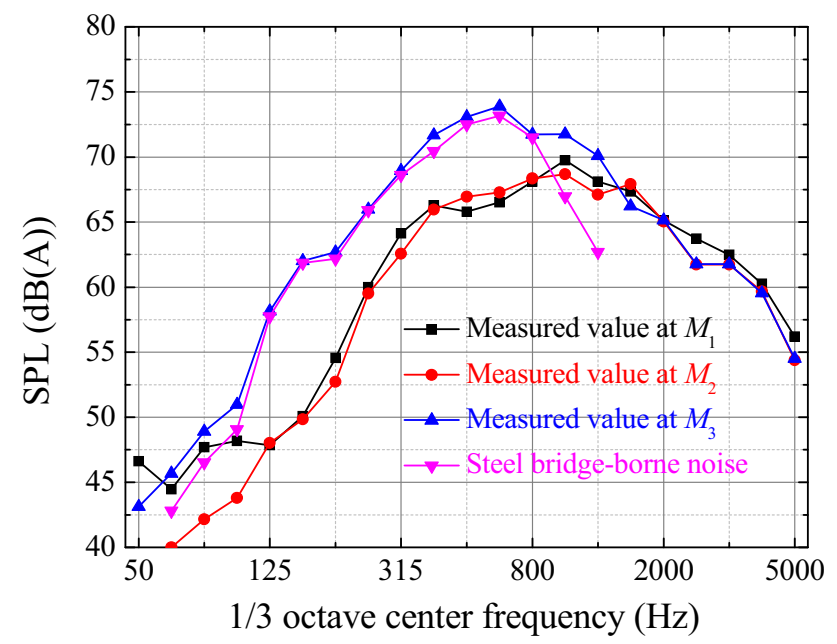

Fig. 9 Test results of the old Arsta Bridge (see Bewes [25])

of trains at speeds of $50-80 \mathrm{~km} / \mathrm{h}$. A measurement point was located $22 \mathrm{~m}$ away from the track centerline at the same height as the rail surface. In addition, a noise reference was measured a few hundred meters away from the bridge at a subgrade section. The results were rearranged and are plotted in Fig. 10; upon train passing, the steel bridge-borne noise was $10-14 \mathrm{~dB}(\mathrm{~A})$ louder than that in the subgrade section. SPL differences appear at a narrow peak frequency of $40 \mathrm{~Hz}$ and across a wider medium-frequency band at $400-630 \mathrm{~Hz}$, which is concentrated in the dominant frequency range of steel bridge-borne noise.

\section{Theoretical studies}

Analytical, numerical analysis, and semi-analytical methods are currently the primary ones applied to analysis of sound radiation from bridge vibrations. Numerical methods

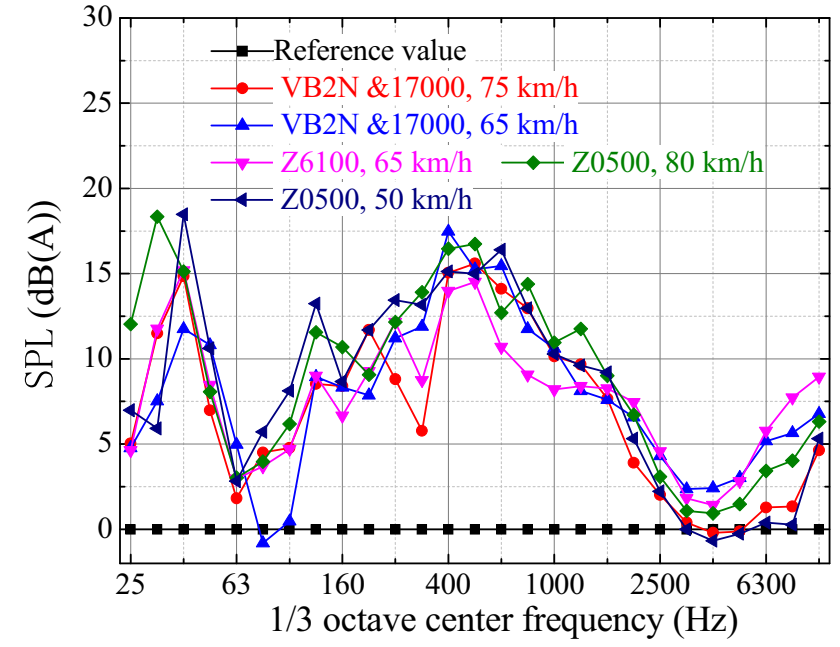

Fig. 10 Reprocessed results from Poisson and Marguicchi [28]

are discrete methods and include the finite element method (FEM), the infinite element method, the BEM, and the energy method (which includes SEA and energy FEM).

The calculation problem of sound radiation can usually be described as a definite solution problem of wave equations under certain boundary conditions [29]. According to different analysis methods, it can be divided into two types: time-domain analysis based on wave equations and frequency-domain analysis based on Helmholtz equations. The former focuses on the vibroacoustic relationship in the time domain and is applicable for calculation of the characteristics of both steady-state and transient acoustics. However, the time-domain analysis method needs to solve a statistical problem at each time step, leading to elevated computational cost and error accumulation. The frequencydomain analysis method employs simple harmonic waves 
as the study object, as an acoustic wave with an arbitrary time functions can always be resolved into a series of simple harmonic sound waves by Fourier transformation. Hence, frequency-domain analysis is especially suitable for the investigation of steady-state acoustic fields and is the most frequently used method in research situations.

\subsection{Semi-analytical method}

Even though it is difficult to use analytical methods to calculate the sound field radiated by a bridge structure, because it is a complex, elastic body noise source, some researchers have analyzed the sound field radiated by the vibration of box-shaped structures. Cui [30] investigated exterior and interior sound radiation from the vibrations of box structures and established a noise prediction theory using the FEM and the virtual boundary element least squares method with fast multipole expansion. The proposed prediction method had high calculation precision, and the predicted results provided useful theoretical support and practical guidelines for engineering noise control of box-shaped structures.

Sun and Xie [31, 32] employed the homogeneous capacity high-precision integration method and the spectrum method of a virtual boundary with a complex radius vector to study box girder sound radiation using Fourier transforms and the stationary phase method. Using these methods, they proposed a high-efficiency, high-precision semi-analytical method of calculating the sound radiation from an infinitely long concrete beam in air. In the above research, the structure had to be simplified to fulfill the analytic solution. For example, the practical box girder was simplified as a cylindrical shell of infinite length [31]. Further, excitations were usually treated as one or more harmonic forces at fixed locations, an oversimplification of real train excitations.

Some studies have used simple noise sources to model noise from such sources as the bridge and wheel-rail interactions. Ouelaa et al. [33] considered train-bridge interactions using the FEM, obtaining SPL values by converting transient bridge accelerations into multiple acoustic monopoles along the bridge. This semianalytical method yields an estimate of bridge noise associated with global rather than local vibrations. Thus, the predicted bridge noise is limited to the very-low-frequency range.

\subsection{Rayleigh integral method}

For an area noise source with arbitrary shapes, the vibratory amplitude and phase at each location on a surface are usually different. Mesh generation can produce an infinite number of small surfaces, and on each of them, the vibration of points can be assumed to be uniform, making it reasonable to take each small surface as a point noise source. Hence, by applying the sound radiation formula at each of the point noise sources, the sound radiation induced by an area noise source of arbitrary shapes can be integrated (i.e., the Rayleigh integral method). This method was first used by Wallace [34] to calculate the radiation resistance of a rectangular panel.

$\mathrm{Au}$ and Wang [35] studied the dynamic response and sound pressure distributions around rectangular orthotropic plates under moving loads in the time domain using the Rayleigh integral method. Although the effects of a moving mass, damping coefficients, boundary conditions, and speed were investigated, the roughness between the plate and the moving force was not considered.

Xie et al. [36, 37] proposed a method for calculating the low-frequency noise radiated by bridge vibrations using a highway vehicle-bridge coupled vibration model and the principle of the Rayleigh integral method. Using a highway steel bridge as an example, a grillage model was applied to calculate the vibratory response of the bridge and the associated low-frequency noise upon a highway vehicle's travel across the bridge. The prediction method was validated by comparison with measured results. Following this, further studies on the influence of parameters such as road surface roughness and vehicle configuration were conducted. The results showed that smooth pavements could reduce the levels of low-frequency bridge-borne noise, and the vehicle simplification model had an impact on computed sound pressures.

The Rayleigh integral method based on the acoustic radiation model was a fairly complete one; however, this method was more suitable for a plate-like structure than one composed of complicated three-dimensional components. Therefore, the prediction accuracy of this method has to be checked for complicated bridge structures.

\subsection{Boundary element method}

The term "boundary element method" (BEM) was coined in 1978 in Brebbia's monograph [38]. The acoustic BEM is mainly based on the Helmholtz integral equations and the Sommerfeld radiation conditions and can be divided into direct and indirect approaches. The former takes SPL and the normal velocity on the structure's surface as boundary conditions; this method is applicable to sound radiation and scattering calculations for closed-surface structures. The indirect method accounts for both the difference in SPL and the velocity on the structure's surface as boundary conditions and is applicable to sound radiation and scattering calculations of open-surface structures.

In recent years, a method that combines the FEM and BEM (i.e., the hybrid FEM-BEM method) has been proposed; it uses the FEM to model structural vibration and 
the BEM to model the acoustic field. This combined method optimizes the characteristics of these two methods and is being generally used in engineering; it can theoretically solve the vibration and sound radiation of a complex elastic structure with arbitrary form.

Zhang et al. [39, 40] proposed the hybrid FEM-BEM method for calculation of box girder noise. A bridge's dynamic response in the time domain can be obtained through solution of the FEM for train-track-bridge coupled vibration; it could then be transferred into the frequency domain via fast Fourier transform. Accordingly, $\mathrm{BEM}$ in the frequency domain takes the velocity of the structural vibration as a sound radiation boundary condition; thus, sound radiation can be estimated using the BEM.

Li et al. [21] similarly used the FEM to model transient train-track-bridge interactions, while the frequency-dependent modal acoustic transfer vector (MATV) method, which is based on the BEM, was applied for acoustic analysis. In that study, SPL in the time domain was obtained using time-frequency transforms. Alternatively, Zhang et al. [41] used a transient BEM to compute the steel bridge-borne noise induced by highway vehicles. Such transient BEM analysis may be time consuming for a railway bridge, because the number of degrees of freedom of a train is typically larger than that of a highway vehicle, and the actual computation efficiency of applying such analysis to trains has not yet been reported.

According to Li et al. [42], computation of MATVs using conventional three-dimensional BEM required prohibitively long times; thus, they presented a two-and-ahalf-dimensional BEM-based procedure. In their study, two-dimensional MATVs were calculated and then transformed into three-dimensional MATVs using space-wave numerical transforms. Fast computational speed was achieved for the case of a 30-m-long, U-shaped girder bridge, which suitably modeled multi-span, simply supported bridges [43]. In recent work [44], the two-and-ahalf-dimensional BEM was extended to predict noise radiated by the rail and bridge at $20-1,000 \mathrm{~Hz}$.

\subsection{Statistical energy analysis}

SEA was first applied in aerospace applications in the early 1960s [45]. For a system with sufficient components, this method, based on statistical physics, effectively describes the mean vibrational intensity and the vibroacoustic characteristics of each component in the high-frequency range. Most random noise and vibration problems cannot be solved using classical methods; SEA thus provides a basis for prediction of the average noise emitted by a structure, especially at high frequencies, where the associated modal density is high.
According to a model proposed by Remington and Witting [46], the generation of bridge-borne noise can be divided into three steps: first, as the train passes, the wheelrail interaction causes the rail and wheel to vibrate; second, the vibratory energy is then transmitted to the bridge structure through the rail fastening, causing various structural components of the bridge to vibrate; and third, the vibrating bridge components, rails, and wheels then radiate sound. This model used the combined wheel-rail roughness as the external excitation. Once the total power input of the bridge was calculated, the distribution of power throughout the bridge structure was determined using simple SEA. Finally, the total sound power radiated by the bridge was calculated using the radiation efficiency of each component. Because this model only accounted for the rail's vertical bending and traveling wave, no wave transmission in the rail was modeled at frequencies below the decoupling one, which is not reasonable. Remington and Witting then compared the noise radiated by an open-deck viaduct with and without rail fastenings; the measured noise levels were compared with the ones computed by the above model. According to the theoretical calculation, the noise level would be reduced by $2 \mathrm{~dB}(\mathrm{~A})$ after installing elastic rail fastenings; the actual reduction was $4 \mathrm{~dB}(\mathrm{~A})$, indicating that the computed results were reasonable. The theoretical model was used further to investigate the effectiveness of several noise reduction measures, and elastic rail fastenings were shown to be the most effective (maximum noise reduction: $10 \mathrm{~dB}(\mathrm{~A})$ ).

On the basis of the research of Remington and Witting, Thompson et al. [47-49] conducted many studies on a track-bridge vibration model. Under that model, first, the bridge combined with the track was considered as an infinitely long Euler-Bernoulli beam with continuous elastic support. Then, the continuous elastic support was replaced by a fixed equivalent point support (i.e., two layers of continuous elastic support were modeled). Finally, discrete point supports were inserted between the track and the bridge to account for the random distribution of support stiffness, sleeper space, and beam mass. This model was used to study problems related to steel-bridge noise and validated SEA for calculation of low-frequency bridge-borne noise. The results showed that SEA is applicable for calculation of sound radiation above $40 \mathrm{~Hz}$ and that sound radiation calculation results below $40 \mathrm{~Hz}$ can be inaccurate.

Li et al. [50] extended the SEA to investigate the structure-borne noise radiated by a $(32+40+32) \mathrm{m}$ steel-concrete composite bridge. In the system of sound radiation induced by bridge vibrations under a running train, the bridge was coupled with both the track structure and the surrounding air fluid. Because of the low density of air and the high stiffness of the bridge structure, the 
interaction between the structure and the radiated sound field was relatively small. Thus, $\mathrm{Li}$ et al. [50] did not account for the coupling reaction between the structure and sound wave or the lack of a fluid subsystem in the SEA model: the track structure comprised part of the vibratory system. The track-bridge coupling reaction was already considered in the train-track-bridge coupled vibration analysis, and the vibratory energy of the bridge deck was linked directly to the track under a coupling reaction. Hence, the net power flow from the track to the bridge deck was used as the input power to the bridge deck. In this way, the SEA model included only the bridge subsystems. Moreover, the vibratory energy of the bridge deck subsystems was known, and the other subsystems' input power was zero. The vibratory energy of each subsystem could thus be obtained by solving the SEA energy balance equations. Finally, sound radiation and SPL at each field point were computed using vibroacoustic theory.

Recently, Zhang et al. [51] presented a hybrid finite element and SEA (hybrid FE-SEA) procedure to predict structure-borne noise from concrete box girder bridges. This method has excellent computational efficiency compared with the widely used three-dimensional BEM, and the case study showed that even the three-span hybrid FESEA model was more efficient than the single-span threedimensional BEM model.

Although the SEA advantageously predicts bridge-borne noise, especially for complicated bridge structures such as steel trusses, several issues need to be considered to ensure prediction accuracy. Three parameters need to be accurately estimated: subsystems' modal density and internal loss factor and the coupling loss factor between subsystems. It is not normally easy to determine these parameters.

\section{Noise reduction control measures}

\subsection{Structural dimensions}

As bridge-slab thickness increases, both structural stiffness and dead weight increase, which makes it difficult to alter the natural vibration frequency. High-order natural vibrations are mainly caused by local vibrations in box girders' decks and bottom slabs, for which stiffness plays a more important role than dead weight. Thus, the natural vibration frequency increases in association with slab thickness.

Zhang et al. [52] studied the influence of structural dimensions on structure-borne noise; their results showed that bridge-borne noise was negatively associated with slab thickness. The overall SPL at each field point was most sensitive to the thickness of the top slab, followed by the web and the bottom slab, respectively, possibly because the deck directly supported both the track structure and upper train load and transmitted them to the bottom slab through the web. Overall, deck stiffness was the most important factor determining a bridge's dynamic response under a running train and thus controlled the noise levels radiated by the structures. Hence, deck thickness could be reasonably increased for the purpose of reducing noise levels. Meanwhile, decreasing web thickness, especially that of the bottom slab, was a feasible noise reduction measure with sufficient carrying capacity; however, this had less influence on structure-borne SPL.

Zhang et al. [52] also studied the influence of web incline on bridge-borne noise. Their results showed that the structure-borne SPL was highest at an incline of $24^{\circ}$, as did results showing the average normal vibratory velocity. When the incline was $12^{\circ}$ or $0^{\circ}$, the overall SPL significantly decreased, and the difference between the SPLs at each point was small, meaning that inclines of $12^{\circ}$ and $0^{\circ}$ had similar noise control effects. Generally, SPL decreased as web inclination decreased; the mechanism of this effect was that the web sustained the deck, so that small web inclinations strengthened the impedance of the entire box girder. Thus, the impedance of the box girder was predicted to reach a maximum for the special case of two webs exactly at the centerline between two rails; in that situation, the best noise control effect was obtained. For the Hong Kong West Rail Line [16], the web of the box girder was adjusted to be just below the track to facilitate decreased bridge vibrations and associated noise.

In conclusion, during bridge design, it is necessary to investigate and adjust relevant parameters, such as the location, thickness, and inclination of the web, to construct quieter bridges and meet the required static and dynamic responses, aesthetic character, and material usage.

\subsection{Cross sections}

Zhang et al. [53] compared the characteristics of a sound field radiated by a single-box, single-cell and single-box, double-cell box girders (Fig. 11). The first-order vibration of the single-box, single-cell box girder was rolling, and there were local vibrations in the deck plate due to the lack of a middle web and the deck plate's large width. In contrast, the first-order vibration of a single-box, double-cell box girder had a vertical bending modality. The vibrational displacement, velocity, and acceleration of the single-cell box girder were larger than those of the double-cell box girder. The SPL of the double-cell box girder was lower than that of a single-cell box girder at the same field observation points and train speed. The SPLs associated with these two types of box girders decreased with the increasing frequency; that of the double-cell box girder was $6 \mathrm{~dB}$ less than that of the single-cell box girder (i.e., the double-cell box girder was quieter). 


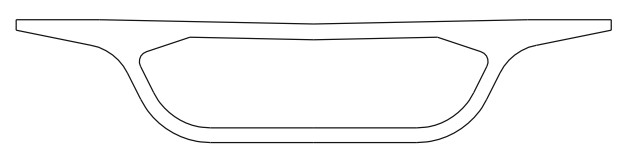

(a)

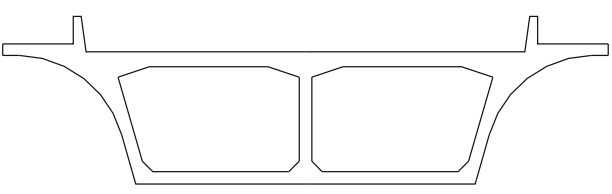

(b)

Fig. 11 Two cross-section types of box girders (see Zhang et al. [53]). a Single-cell, b double-cell

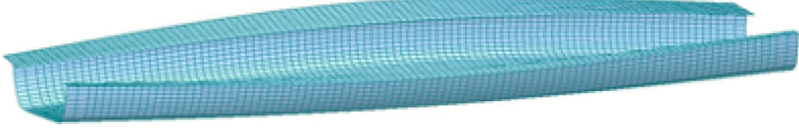

Fig. 12 Typical local vibrational mode of a U-shaped girder (see Zhang et al. [27])

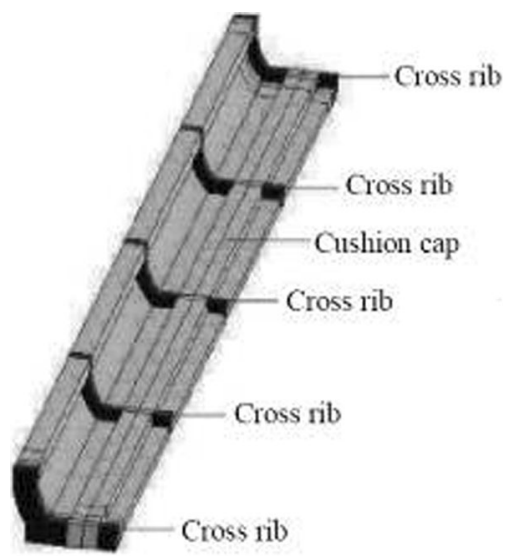

Fig. 13 Cross ribs reducing noise from a U-shaped girder (see Han et al. [54])

Zhang [27] compared a U-shaped girder with a box girder in terms of structural noise. Because of its open cross section, the U-shaped girder had lower flexure frequencies and significant local vertical vibrations in the bottom slab (see Fig. 12), which led to obvious bending-torsion coupled vibrations. Even though the train load running on the U-shaped girder bridge was usually smaller than that running on the single-track box girder bridge, the bridge-borne noise of the U-shaped girder exceeded that of the box girder because of the former's low stiffness and high vibration responses. This conclusion was also verified by results measured by $\mathrm{Wu}$ and Liu [22].

Han et al. [54] discussed the influences of plate thickness and cross ribs on the noise from a U-shaped girder (Fig. 13). The numerical simulation showed that the bottom slab of the U-shaped girder played a more important role than the web in the production of structural noise in the

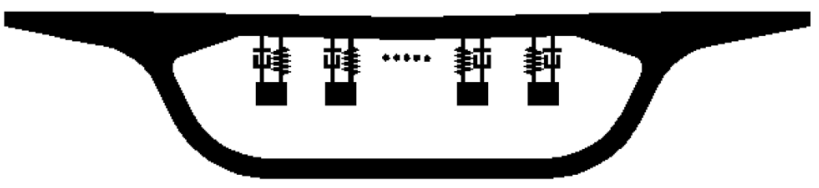

Fig. 14 MTMDs hanging in a box girder below the top slab (see Zhang et al. [55])

far-field region, and that increasing the bottom slab thickness more effectively reduced structural noise than increasing the web thickness. The addition of cross ribs also reduced structural noise in the far-field region and near the girder bottom. Moreover, the addition of cross ribs over the whole span was more effective than midspan concentration of cross ribs. Such noise reduction was more effective at higher than lower train speeds.

\subsection{Tuned mass dampers}

The use of a tuned mass damper (TMD) is effective for controlling structural vibration and is generally applied to structural vibrations caused by earthquakes or winds. In recent decades, TMD systems have been gradually implemented to control train-induced structural vibration. However, TMDs have relatively poor robustness, and their vibration control effect significantly decreases with drift of the structural vibration frequency. To solve this problem, researchers have proposed using multiple tuned mass dampers (MTMDs) to control structural vibration with changing frequency and vertical vibration of bridge structure.

Zhang et al. [55] studied the effectiveness of MTMDs on bridge-borne noise (Fig. 14). The results showed that MTMDs affected a bridge's control of the maximum vibratory response but had little effect on structure-borne noise. They could only reduce noise $25 \mathrm{~m}$ from the neartrack centerline by an average of about $0.5 \mathrm{~dB}$.

MTMDs work only with the first-order vertical bending vibration, whereas structure-borne noise was caused mainly by high-order local vibrations. Bridge-borne noise has a more complex mechanism than that of structural vibration; the value of bridge-borne noise depends not only 
on structural vibration but also on the structure's topological shape, radiation efficiency, vibration distribution, transmission media, and transmission route. Thus, it is not feasible to reduce structural noise only by controlling the maximum train-induced bridge vibration. That is, the application of MTMDs designed for low-order modes for structural vibration control cannot similarly control structure-borne noise. Hence, investigation of MTMDs for controlling high-order structural vibration modes is critical to the reduction of bridge-borne noise.

Gan et al. [56] studied the possibility of using tuned liquid dampers (TLDs) to reduce bridge-borne vibration and noise. Numerical results demonstrated that the average noise reduction around the box girder's web was about $5 \mathrm{~dB}$; however, the engineering application of TLDs needs to be considered carefully. For instance, it is not easy to contain liquid in the interior space of a box girder.

\subsection{Track structures}

Track structural parameters play an important role in the load transmitted to the bridge structure, because such parameters transmit directly to the train load. Zhang et al. [57] studied the influences of stiffness and damping of rail fastenings on box girder noise; the peak frequency of structural noise ranged $40-80 \mathrm{~Hz}$ and was determined mainly by the stiffness of the rail fastening. At field points $1.2 \mathrm{~m}$ above the ground and $10-40 \mathrm{~m}$ and $40-100 \mathrm{~m}$ from the near-track centerline, the SPL attenuation rates were 0.29 and $0.067 \mathrm{~dB} / \mathrm{m}$, respectively. Increased fastening stiffness could effectively decrease the directivity angle of bridge-borne noise. The SPL of the vertical section $30 \mathrm{~m}$ from the near-track centerline increased by an average of $12.5 \mathrm{~dB}$ with an increase in fastening stiffness from 10 to $100 \mathrm{MN} / \mathrm{m}$; in addition, the peak frequencies of the structure-borne noise and the wheel-rail interaction force increased from 30 to $67 \mathrm{~Hz}$. As the fastening damping ratio increased from 0.0625 to 0.5 , the SPL of the vertical section $30 \mathrm{~m}$ from the near-track centerline decreased by an average of $5.0 \mathrm{~dB}$, while the peak frequency of the structure-borne noise and the wheel-track interaction force remained constant. Results showed that the fastening damping ratio had a relatively small influence on the directivity angle of the bridge-borne noise alongside the bridge.

Results by Liu and Yang [58] showed that a ladder sleeper and floating track could reduce bridge-borne noise in the frequency range $40-80 \mathrm{~Hz}$ compared with a common monolithic track bed. In a case with a fully closed sound barrier on an elevated bridge, the ladder sleeper decreased the SPL by $3.6 \mathrm{~dB}(\mathrm{~A})$ in the frequency range $12.5-250 \mathrm{~Hz}$ at $0.3 \mathrm{~m}$ below the bridge girder. The floating track decreased the SPL by $4.0 \mathrm{~dB}(\mathrm{~A})$.
The two aforementioned cases prove that a vibration reduction track can considerably mitigate bridge noise. However, another noise source that is likely to be overlooked is track structures, such as floating tracks, that absorb significant amounts of energy and thus radiate more noise than common track structures.

\subsection{Constrained layer damping}

Liu [26] studied the use of constrained layer damping (CLD) to reduce steel bridge-radiated noise and successfully applied the CLD noise reduction technique to a steelconcrete composite bridge on a high-speed railway.

Field measurements were conducted on a steel-concrete composite bridge before and after CLD installation. CLD was laid over $328.23 \mathrm{~m}^{2}$ of the bridge, adding $6,138.8 \mathrm{~kg}$ to the dead load. With CLD laid on the bottom slab of the composite bridge, the effective acceleration values on the web and bottom flange were reduced by 1.5 and $0.5 \mathrm{~m} / \mathrm{s}^{2}$, respectively. Meanwhile, the vibratory acceleration was reduced in the main frequency range, and the SPL underneath the bridge was reduced by $2-4 \mathrm{~dB}(\mathrm{~A})$ at different train speeds. Moreover, in the medium- and high-frequency regions (i.e., frequencies $>125 \mathrm{~Hz}$ ), the noise from bridge vibrations obviously decreased.

Numerical results show that after CLD placement, the radiated structural noise was effectively reduced across the entire audible spectrum, with the decrease in SPL ranging 3.9-4.3 $\mathrm{dB}(\mathrm{A})$ at different field points. Moreover, the SPL decrease underneath the bridge was greater than that above the bridge. The vibratory velocity of the longitudinal girder web and bottom flange decreased by 10.5 and $6.1 \mathrm{~dB}$, respectively, showing excellent effectiveness.

\section{Conclusions}

The present paper has reviewed experimental and theoretical studies on bridge-borne noise. The space distribution, spectral characteristics, and SPL of noise radiated by bridges were briefly analyzed. Then, the results of experimental studies conducted by the authors and other investigators on concrete bridges, steel-concrete composite bridges, and all-steel bridges were summarized. Four methods for theoretical analysis of bridge-borne noise were introduced: the Rayleigh integral method, the semi-analytical method, the BEM, and the SEA method. Finally, on the basis of current research results, five kinds of noise control measures were reviewed, resulting in the following conclusions:

(1) The dominant frequencies of concrete bridge-borne noise (including box girder and U-shaped girder 
bridges) are below $100 \mathrm{~Hz}$, controlled by local vibrations rather than global vibrations. However, the dominant noise frequencies from steel-concrete composite and steel bridges can be as high as several hundred $\mathrm{Hz}$.

(2) Sound radiation from bridges is influenced by building material, structural type, structural size, boundary conditions, train loading frequencies, and track irregularities.

(3) The hybrid FEM-BEM numerical simulation method is a good predictor of noise from concrete bridges, while SEA is more suitable for the prediction of noise from steel bridges. In both prediction methods, traintrack-bridge coupling vibration analysis is the first key step in determining bridge vibration responses or energy input. Presently, BEM and SEA are the most popular numerical analysis methods, and they can theoretically be used for any type of bridge.

(4) Variations to structural dimensions and cross-section type can provide effective control measures for noise reduction from concrete bridges. TLD and MTMDs are potential control measures whose effectiveness and applicability need to be studied further. The use of softer fastenings has obvious vibration and noise reduction effects. For medium- and high-frequency noise radiated by steel-concrete composite and steel bridges, the CLD technique is a highly effective noise mitigation measure.

Acknowledgments The authors are grateful for financial support from the National Natural Science Foundation of China (Grant Nos. 51308469 and 51378429) and the International Cooperation Program of Sichuan Province (Grant No. 2016HH0076).

Open Access This article is distributed under the terms of the Creative Commons Attribution 4.0 International License (http:// creativecommons.org/licenses/by/4.0/), which permits unrestricted use, distribution, and reproduction in any medium, provided you give appropriate credit to the original author(s) and the source, provide a link to the Creative Commons license, and indicate if changes were made.

\section{References}

1. Thompson DJ (2009) Railway noise and vibration: mechanisms, modeling and means of control. Elsevier Ltd, Oxford

2. Xia H (2010) Traffic induced vibrations and controls. Science Press, Beijing (in Chinese)

3. Bengtsson J, Waye KP, Kjellberg A (2004) Evaluations of effects due to low-frequency noise in a low demanding work situation. J Sound Vib 278:83-99

4. Broner N (2010) A simple criterion for low frequency noise emission assessment. J Low Freq Noise Vib Act 29(1):1-13

5. Stüber C (1975) Air- and structure- borne noise of railways. J Sound Vib 43:281-289
6. Office for Research and Experiment (ORE) of the Union Internationale des Chemins de Fer (1966) Question D105, noise abatement on bridges. Report RP1. Noise development in steel railway bridges

7. Office for Research and Experiment (ORE) of the Union Internationale des Chemins de Fer (1969) Question D105, noise abatement on bridges. Report RP2. Noise measurements on Rosenheim bridges

8. Office for Research and Experiment (ORE) of the Union Internationale des Chemins de Fer (1971) Question D105, noise abatement on bridges. Report RP3. Final report

9. Xia H, Gao F, Wu X, Zhang N, De Roeck G, Degrande G (2009) Running train induced vibrations and noises of elevated railway structures and their influences on environment. Front Archit Civ Eng China 3(1):9-17

10. Ban Y, Miyamoto T (1975) Noise control of high-speed railways. J Sound Vib 43:273-280

11. Kurzweil LG (1977) Prediction and control of noise from railway bridges and tracked transit elevated structures. J Sound Vib $51: 419-439$

12. Ungar EE, Wittig LE (1980) Wayside noise of elevated rail transit structure: analysis of published data and supplementary measurements. US Department of Transportation report

13. Walker JG, Ferguson NS, Smith MG (1996) An investigation of noise from trains on bridges. J Sound Vib 193:307-314

14. Wang A, Cox SJ, Gosling D, Prudhoe JE (2000) Railway bridge noise control with resilient baseplates. J Sound Vib 231:907-911

15. Ngai KW, Ng CF (2002) Structure-borne noise and vibration of concrete box structure and rail viaduct. J Sound Vib 255:281-297

16. Ngai KW (2004) The model of local mode analysis for structural acoustics of box structures. Dissertation, The Hong Kong Polytechnic University, Hong Kong

17. Li XZ, Zhang X, Zhang ZJ, Liu QM, Li YD (2015) Experimental research on noise emanating from concrete box-girder bridges on intercity railway lines. Proc Inst Mech Eng Part F J Rail 229(2):125-135

18. Zhang X, Li XZ, Song LZ, Su B, Li YD (2016) Vibrational and acoustical performance of concrete box-section bridges subjected to train wheel-rail excitation: field test and numerical analysis. Noise Control Eng J 64(2):217-229

19. Chang $L$ (2008) The research on vibration and noise radiation of box beam. Dissertation, Wuhan University of Technology, Wuhan (in Chinese)

20. Gao F, Xia H, Cao YM, An N (2012) Analysis of elevated structure radiated noise with BEM-FEM method. J Civ Archit Environ Eng 34:42-46 (in Chinese)

21. Li Q, Xu YL, Wu DJ (2012) Concrete bridge-borne low-frequency noise simulation based on train-track-bridge dynamic interaction. J Sound Vib 331:2457-2470

22. Wu TX, Liu JH (2012) Sound emission comparisons between the box-section and U-section concrete viaducts for elevated railway. Noise Control Eng J 60(4):450-457

23. Li Q, Wu DJ (2013) Analysis of the dominant vibration frequencies of rail bridges for structure-borne noise using a power flow method. J Sound Vib 332:4153-4163

24. Zhang X, Li XZ, Hao H, Wang DX, Li YD (2016) A case study of interior low-frequency noise from box-shaped bridge girders induced by running trains: its mechanism, prediction and countermeasures. J Sound Vib 367:129-144

25. Bewes OG (2005) The calculation of noise from railway bridges and viaducts. Dissertation, University of Southampton, Southampton

26. Liu QM (2015) Prediction of structure-borne noise from railway composite bridge and suppression study of constrained layer damping. Dissertation, Southwest Jiaotong University, Chengdu (in Chinese) 
27. Zhang X (2012) Study on the prediction and control of structureborne noise of rail transit bridges. Dissertation, Southwest Jiaotong University, Chengdu (in Chinese)

28. Poisson F, Margiocchi F (2006) The use of dynamic dampers on the rail to reduce the noise of steel railway bridges. J Sound Vib 293:944-952

29. Fahy FJ, Gardonio P (2007) Sound and structural vibration: radiation, transmission and response, 2nd edn. Academic Press, Oxford

30. Cui Z (2003) Theoretical prediction of sound field radiated from a complex box structure and the noise control. Dissertation, Xi' an Jiaotong University, Xi'an (in Chinese)

31. Xie WP, Sun LM (2008) Semi-analytical method of acoustic radiation from box beam. J Wuhan Univ Technol 30(12):165-169 (in Chinese)

32. Sun LM (2008) Theoretical study on structural noise of box beam. Dissertation, Wuhan University of Technology, Wuhan (in Chinese)

33. Ouelaa N, Rezaiguia A, Laulagnet B (2006) Vibro-acoustic modelling of a railway bridge crossed by a train. Appl Acoust 67(5):461-475

34. Wallace CE (1972) Radiation resistance of a rectangular panel. J Acoust Soc Am 51(3):946-952

35. Au FTK, Wang MF (2005) Sound radiation from forced vibration of rectangular orthotropic plates under moving loads. J Sound Vib 281:1057-1075

36. Xie X, Zhang H, Yamashita M, Zhang ZC (2008) Theoretical analysis of low-frequency noise radiated from bridge vibrations. China Civ Eng J 41(10):53-59 (in Chinese)

37. Xie X, Wu DY, Zhang H, Shen YG, Yamashita M (2012) Lowfrequency noise radiation from traffic-induced vibration of steel double-box girder bridge. J Vib Control 18(3):373-384

38. Brebbia CA (1978) The boundary element method for engineers. Pentech Press, London

39. Zhang X, Li XZ, Liu QM, Wu JF, Li YD (2013) Theoretical and experimental investigation on bridge-borne noise under moving high-speed train. Sci China Technol Sci 56(4):917-924

40. Zhang X, Li XZ, Li YD, Liu QM, Zhang ZJ (2013) Train-induced vibration and noise radiation of a prestressed concrete box-girder. Noise Control Eng J 61(4):425-435

41. Zhang H, Xie X, Jiang JQ, Yamashita M (2015) Assessment on transient sound radiation of a vibrating steel bridge due to traffic loading. J Sound Vib 336:132-149

42. Li Q, Song XD, Wu DJ (2014) A 2.5-dimensional method for the prediction of structure-borne low-frequency noise from concrete rail transit bridges. J Acoust Soc Am 135(5):2718-2726

43. Song XD, Wu DJ, Li Q, Botteldooren D (2016) Structure-borne low-frequency noise from multi-span bridges: a prediction method and spatial distribution. J Sound Vib 367:114-128
44. Song XD, Li Q, Wu DJ (2016) Investigation of rail noise and bridge noise using a combined 3D dynamic model and 2.5D acoustic model. Appl Acoust 109:5-17

45. Yao DY, Wang QZ (1995) Principle and application of statistical energy analysis. Beijing Institute of Technology Press, Beijing (in Chinese)

46. Remington PJ, Wittig LE (1985) Prediction of the effectiveness of noise control treatments in urban rail elevated structures. J Acoust Soc Am 78(6):2017-2033

47. Janssens MHA, Thompson DJ (1996) A calculation model for the noise from steel railway bridges. J Sound Vib 193(1):295-305

48. Harrison MF, Thompson DJ, Jones CJC (2000) The calculation of noise from railway viaducts and bridges. Proc Inst Mech Eng Part F J Rail 214(3): 125-134

49. Bewes OG, Thompson DJ, Jones CJC, Wang A (2006) Calculation of noise from railway bridges and viaducts: experimental validation of a rapid calculation model. J Sound Vib 293:933-943

50. Li XZ, Liu QM, Pei SL, Song LZ, Zhang X (2015) Structureborne noise of railway composite bridge: numerical simulation and experimental validation. J Sound Vib 353:378-394

51. Zhang X, Li XZ, Zhang JQ, Song LZ, Li YD (2015) A hybrid FESEA model for the prediction of low-frequency noise emanating from a concrete box-girder railway bridge. Proc Inst Mech Eng Part F J Rail. doi:10.1177/0954409715605127

52. Zhang X, Li XZ, Liu QM et al (2013) Study on structure-borne noise of concrete box-girder and its influence factors. J Southwest Jiaotong Univ 48(3):409-414 (in Chinese)

53. Zhang X, Li XZ, Liu DJ, Li YD (2012) Sound Radiation Characteristics of 32 meters simply supported concrete box girder applied in high-speed railway. J China Railw Soc 34(7):96-102 (in Chinese)

54. Han JL, Wu DJ, Li Q (2012) Influence of deck thickness and stiffeners on structure-borne noise of the trough beams. J Vib Eng 25(5):589-594 (in Chinese)

55. Zhang X, Li XZ, Liu QM, Zhang ZJ, Li YD (2013) Study of MTMDs on the structure-borne noise control of high-speed railway simply supported box-girder bridge. J Vib Shock 32(13):194-200 (in Chinese)

56. Gan L, Lei ZY, Yan X (2015) Control simulation of TLD in rail transit for vibration and noise reduction on box girder bridges. Urban Mass Transit 8:46-51 (in Chinese)

57. Zhang X, Su B, Li XZ (2015) Effects of fastener stiffness and damping on structure-borne noise of railway box-girders. J Vib Shock 34(15):150-155 (in Chinese)

58. Liu PH, Yang YQ (2014) Vibration and noise reduction tests on the first-stage project of an domestic elevated bridge. Final Report. (in Chinese) 